\title{
Comparative Analysis on EWMA and Poisson Cusum Chart in the Assessment of Road Traffic Crashes (RTC) in Osun State Nigeria
}

\author{
Faweya Olanrewaju ${ }^{1,}$, Ogunwale Olukunle Daniel ${ }^{1}$, Adeniran Adefemi Tajudeen ${ }^{2}$ \\ ${ }^{1}$ Department of Statistics, Ekiti State University, Ado Ekiti, Nigeria \\ ${ }^{2}$ Department of Statistics, University of Ibadan, Ibadan, Nigeria
}

Email address:

lanrefaweya@gmail.com (F. Olanrewaju)

*Corresponding author

\section{To cite this article:}

Faweya Olanrewaju, Ogunwale Olukunle Daniel, Adeniran Adefemi Tajudeen. Comparative Analysis on EWMA and Poisson Cusum Chart in the Assessment of Road Traffic Crashes (RTC) in Osun State Nigeria. American Journal of Theoretical and Applied Statistics. Vol. 6, No. 2, 2017, pp. 95-99. doi: 10.11648/j.ajtas.20170602.14

Received: October 14, 2016; Accepted: January 31, 2017; Published: March 10, 2017

\begin{abstract}
This study examines the daily Road Traffic Crashes (RTC) casualties in Osun state of Nigeria, Comparison of two quality control schemes identified as exponential Weighted Moving Average (EWMA) and Poisson Cumulative sum (CUSUM) control chart techniques were made using data collected from Federal Road Safety Corps (FRSC) Osun-State over a period 120 months our findings revealed that both techniques are capable of detecting small shift from mean level but Cusum is more sensitive. Furthermore, the points of change in the process are clearly identified and easily located on both schemes. The findings provide a proper diagnostic solution in the area of Road Traffic crash (RTC) reduction and control in Osun state Nigeria.
\end{abstract}

Keywords: Road Traffic Crashes (RTC) Casualties, Osun State, EWMA Control Chart, Poisson Cusum Control Chart

\section{Introduction.}

Road Traffic Crashes (RTC) have turned out to be a major global public health and development problem (Asogwa 1978). As a matter of fact, World Health Organization estimated that about 1.2 million people die annually from road traffic crashes of which 1.07 million of these are from low and middle income countries (peder et al,2006) of which Nigeria belongs. The impact of RTC is an economic, social, physical, psychological and public health challenge (WHO, 2004).

In Nigeria, 5,255 motor traffic crashes were recorded between Jan and June 1914 resulting in 3,254 deaths with 15,587 people sustaining injury (FRSC Website 2014). The annual loss in property resulting from RTC is put at over 100 billion Naira (the punch, 2002). In the USA, polanis (1995) estimated that the loss in property due to RTC was about 65 billion dollars in 1990 rising to 72 billion dollars by 1991 . The world Health Organization stated that RTC has become the second leading cause of death after HIV/AIDS among 15-
29 years old in low and middle-income countries. It also by year 2030, RTC will rank $7^{\text {th }}$ among the major diseases and injuries in the world (peden et al, 2006). Hence urgent attention is needed on road transportation system in order to minimize or eradicate RTC casualties.

RTC in Nigeria have been described as an important cause of mortality with the need for a comprehensive RTC preventive programme (Onadeko, 1983). The need to curb the excessive high rate of RTC in Nigeria has led to the establishment of the federal Road safety corps (FRSC) by the federal Government of Nigeria in 1988 with the aim to make the highways safe for the motorists and other road users. The FRSC is changed with the duty of educating the motorists and member $\mathrm{s}$ of the public on essence of discipline on highways, enforcement of traffic rates regulations and paying attention and care to RTC casualties among others.

In this study, EMWA and poisson CUSUM Control charts are employed in monitoring RTC causalities that Occurred between January 2010 and April 2014 in Osun state, Nigeria. The data used was collected from the FRSC, OSUN 
command. These designed charts are used to detect the peak and the cumulated trend for RTC casualties that appropriate actions. World be taken by road managers in their effort to minimize RTC causalities.

\section{Methodology}

\subsection{Design of EWMA Control Chart}

EWMA control chart is one of the good alternatives to the she what control chart when we are interested in detecting small shifts (Montgomery, 2005). It's performance is approximately equivalent to that of the cussum control chart, and in some ways it is easier to set up and operate. It is typically used with individual observations.

Robots (1959) introduced the EWMA control chart, it is sometimes called a geometric moving average (GMA). It is used extensively in time series modeling and in forecasting (box, jenking, and remsel, 1994; Montgomery et al 1990). Since the EMWA can be viewed as a weighted average of al past and current observations.

For monitoring the process mean, the EMWA control chart consists of plotting:

$$
z_{i}=\lambda x_{i}+(1-\lambda) z_{i-1}, 0<\lambda \leq 1
$$

Versus time $\mathrm{t}$ (or sample 1).

Where $\lambda$ is a constant and the starting value (required with the first sample $\mathrm{i}=1$ ) is the process so that $z_{0}=\mu_{0}$. At times the average of preliminary data is used as the starting value of the EWMA so that $z_{0}=\bar{x}$.

In this equation $\mathrm{x}$ is the sample mean from time period $\mathrm{t}, z_{i}$ is the plotted test statistic and $\lambda$ is the weight assigned to the current observation. The equation of the EWMA test statistic given in (1) can be applied to monitor any process parameter of interest.

In general, typical values of $\lambda$ in the interval $0.05 \leq \lambda \geq$ 0.25 work well in practice, with $\lambda 0.05,0.10$, and 0.20 being a popular choices, although larger values may be used in forecasting and control applications. A good rule of thumb is to use smaller values of $\lambda$ to detect smaller shifts. Also, $\mathrm{L}=3$ (the usual three sigma limits) works reasonably well, particularly with the large value of $\lambda$, although when $\lambda$ is small say, $\lambda \leq 0.1$, there is an advantage on reducing the width of the units by using a value between 2.6 and 2.8 .

Upper control limit (UCL) control limit (CL) and Lower control Limit (LCL) for the EWMA control chart are given respectively as:

$$
\begin{gathered}
\mathrm{UCL}=\mu_{0}+\mathrm{L} \sigma \sqrt{\frac{\lambda\left[1-(1-\lambda)^{2 i}\right.}{(2-\lambda)}} \\
\mathrm{CL}=\mu_{0} \\
\mathrm{LCL}=\mu_{0}-\mathrm{L} \sigma \sqrt{\frac{\lambda\left[1-(1-\lambda)^{2 i}\right.}{(2-\lambda)}}
\end{gathered}
$$

$\sigma=$ standard deviation of the object $x_{i}$.

$\mathrm{L}=$ Width of the control limits.

If the sample means fall within the control limits then we can say that the process is in control with respect to the mean process while the process will be out of control if the sample means exceed the control limits.

As I increases, the term $\left[1-(1-\lambda)^{2 i}\right]$ tends to unity. This implies that after the EWMA control has been running for several time periods, the control limits will approach steady state values.

$$
\begin{gathered}
\mathrm{UCL}=\mu_{0}+\mathrm{L} \sigma \sqrt{\frac{\lambda}{(2-\lambda)}} \\
\mathrm{CL}=\mu_{0} \\
\mathrm{LCL}=c-\mathrm{L} \sigma \sqrt{\frac{\lambda}{(2-\lambda)}}
\end{gathered}
$$

However, it is advisable to use the exact control limits. This will greatly improve the performance of the control chart in detecting an off target process immediately after the EWMA is started up. The EWMA control chart is always use with individual measurements. However, if rational subgroups of size $\mathrm{n} \geq 1$ are taken, then simply replace $x_{i}$ with sample mean $\bar{x}$ and $\sigma$ with sample standard deviation $\sigma_{\bar{x}}=$ $\frac{\sigma}{\sqrt{n}}$.

\subsection{Design of Poisson Cussum Chart}

The design procedure for poisson cusum for detecting an increase in count rate involves how to choose the reference value $(\mathrm{k})$ and the decision interval value $(\mathrm{h})$. the parameter $\mathrm{h}$ is primarily obtained by the desired in-control Average Run length (ARL), That is, the acceptable frequency of false outof-control signals. After $\mathrm{k}$ is selected, the decision interval $\mathrm{h}$ is determined from tables.

\subsubsection{Determining the Value of $K$}

The parameter $\mathrm{k}$ is the reference value for the cussum scheme. For a poisson CUSUM, the reference value $\mathrm{k}$ depends on the acceptable count rate $\left(\mu_{a}\right)$ and on the count rate that is to be detected quickly $\left(\mu_{d}\right)$. Lucas (1985) gave the expression for determining reference value $k_{b}$ for the poisson CUSUM as

$$
k_{b}=\left(\mu_{-} d-\mu_{-} a\right) /\left(\ln \mu_{-} d-\ln \mu_{-} a\right)
$$

It is necessary to wrote that if the time scale for the poisson cussum is the same as the time scale for the time between - events cussum, the reference value $\mathrm{k}$ for the time between-events cussum is the reciprocal of the reference value $k_{p}$ for the poisson cussum.

\subsubsection{Determining the Value of $\mathrm{H}$}

After chosen $\mathrm{k}$, the decision interval value (h) is obtained from the table extracted from poissoncussum Average from length (AR1) with or without fast initial response (FIR), that uses a normalized reference value $k_{t}=k_{b x \mu_{a}}$. Alternatively, $k_{t}$ may be to determined from the $\frac{\mu_{d}}{\mu_{a}}$ ratio;

$$
k_{t}=\frac{\left(\ln \left(\frac{\mu_{d}}{\mu_{a}}\right)\right)}{\left(\left(\frac{\mu_{d}}{\mu_{a}}\right)\right)-1} .
$$


The value of $h$ should give an appropriately large ARL when the process is at its desired Acceptable Quality level (AQL) and an appropriately small ARL value when the process has shifted to an undesired rejectable Quality level (RQL).

The most common application of a time-between-events cussum is to detect a decrease in the time-between counts and the ARL for this cussum is the average number of events before an out of control signal occurs.

In a time-between-events cussum, the time between out-ofcontrol signals is directly proportional to ARL of $\frac{\mu_{d}}{\mu_{a}}$. In order to implement a time - between -events cussum, the $h_{t}$ value obtained from the table is normalized to determine the decision interval value $\left(h_{b}\right)$ used by the control scheme with $h_{b}=\frac{h_{t}}{\mu_{a}}$

The cussum formula used is

$$
s_{i}=\max \left(0, y_{i}-k+s_{(i-1)}\right)
$$

And

$$
s_{i}=\min \left(0, \mathrm{k}-y_{i}+s_{(i-1)}\right)
$$

For detection of mere use and decrease in time - betweenevents respectively.

Whenever $s_{i} \geq \mathrm{h}$, an alarm is signaled in implementing the time - between - - events cussum, the parameter values $h_{b}$ and $k_{b}$ will be substituted for $\mathrm{h}$ and $\mathrm{k}$.

\section{Results and Discussion}

\begin{tabular}{|c|c|c|c|c|c|c|c|c|c|c|c|c|c|c|}
\hline YEAR & JAN & FEB & MAR & APRIL & MAY & JUNE & JULY & AUG & SEPT & OCT & NOV & DEC & SUM & AVER \\
\hline 2005 & 38 & 57 & 54 & 48 & 88 & 36 & 66 & 38 & 57 & 65 & 68 & 83 & 698 & 58.16 \\
\hline 2006 & 64 & 63 & 64 & 46 & 57 & 52 & 59 & 42 & 78 & 55 & 93 & 67 & 740 & 61.66 \\
\hline 2007 & 60 & 49 & 20 & 58 & 71 & 73 & 54 & 73 & 71 & 56 & 66 & 50 & 701 & 58.41 \\
\hline 2008 & 72 & 74 & 61 & 82 & 75 & 70 & 55 & 57 & 71 & 58 & 83 & 72 & 830 & 69.16 \\
\hline 2009 & 52 & 52 & 58 & 89 & 63 & 45 & 56 & 76 & 73 & 59 & 75 & 47 & 745 & 62.08 \\
\hline 2010 & 24 & 9 & 20 & 19 & 16 & 17 & 12 & 18 & 28 & 21 & 28 & 30 & 242 & 20.16 \\
\hline 2011 & 24 & 14 & 23 & 22 & 21 & 14 & 18 & 16 & 18 & 24 & 40 & 36 & 270 & 22.5 \\
\hline 2013 & 28 & 33 & 28 & 19 & 28 & 34 & 20 & 17 & 26 & 19 & 15 & 28 & 295 & 24.58 \\
\hline 2014 & 26 & 24 & 21 & 19 & 20 & 19 & 17 & 29 & 26 & 29 & 19 & 23 & 272 & 22.66 \\
\hline
\end{tabular}

Table 1. Data on Daily Road Traffic Crashes ( $R$ T C) Casualties in Osun State.

From the data for 120 months, the overall mean per month is $\bar{x}=42$ and the standard deviation $\sigma=22$.

Thus, in order to detect changes in the mean level of accident causalities during this period, the acceptable mean level is chosen nearer to the current mean level, i. e $\mu_{0}=42$ and standard deviation, $\sigma=22$.

Suppose the authority demands a shift of $1 \sigma$ from $\mu_{o}$ to be the rejectable level, then a shift of $1 \sigma$ in the positive direction yields $\mu_{1}=\mu_{0}+1 \sigma=64$.

$$
\begin{aligned}
\mathrm{K} & =\frac{\mu 1-\mu \mathrm{o}}{\ln \mu 1-\mu \mathrm{o}} \\
\mathrm{K} & =\frac{64-42}{\ln 64-\ln 42} \\
& =52.23
\end{aligned}
$$

\begin{tabular}{|c|c|c|c|c|c|c|c|}
\hline MONTH(i) & (Xi) & $\mathbf{C}^{+}$ & $\mathbf{N}^{+}$ & MONTH (i) & $(\mathbf{X i})$ & $\mathbf{C}^{+}$ & $\mathbf{N}^{+}$ \\
\hline 1 & 38 & 0 & 0 & 61 & 24 & 0 & 0 \\
\hline 2 & 57 & 0 & 0 & 62 & 9 & 0 & 0 \\
\hline 3 & 54 & 0 & 0 & 63 & 20 & 0 & 0 \\
\hline 4 & 48 & 0 & 0 & 64 & 19 & 0 & 0 \\
\hline 5 & 88 & 25 & 1 & 65 & 16 & 0 & 0 \\
\hline 6 & 36 & 9 & 2 & 66 & 17 & 0 & 0 \\
\hline 7 & 66 & 32 & 3 & 67 & 12 & 0 & 0 \\
\hline 9 & 57 & 55 & 5 & 69 & 28 & 0 & 0 \\
\hline 10 & 65 & 82 & 6 & 70 & 21 & 0 & 0 \\
\hline 11 & 68 & 125 & 7 & 71 & 28 & 0 & 0 \\
\hline 12 & 83 & 199 & 8 & 72 & 30 & 0 & 0 \\
\hline 13 & 64 & 12 & 9 & 73 & 24 & 0 & 0 \\
\hline 14 & 63 & 35 & 10 & 74 & 14 & 0 & 0 \\
\hline 15 & 64 & 70 & 11 & 75 & 23 & 0 & 0 \\
\hline 18 & 52 & 167 & 14 & 78 & 14 & 0 & 0 \\
\hline 19 & 59 & 208 & 15 & 79 & 18 & 0 & 0 \\
\hline
\end{tabular}

Approximately 52

The reference value $\mathrm{K}$ is computed using

Table 2. Tabular Cusum for the Road Traffic Crash (RTC) Casualties in Osun State. 


\begin{tabular}{|c|c|c|c|c|c|c|c|}
\hline MONTH(i) & (Xi) & $\mathbf{C}^{+}$ & $\mathbf{N}^{+}$ & MONTH (i) & (Xi) & $\mathbf{C}^{+}$ & $\mathbf{N}^{+}$ \\
\hline 20 & 42 & 239 & 16 & 80 & 16 & 0 & 0 \\
\hline 21 & 78 & 296 & 17 & 81 & 18 & 0 & 0 \\
\hline 22 & 55 & 356 & 18 & 82 & 24 & 0 & 0 \\
\hline 23 & 93 & 457 & 19 & 83 & 40 & 0 & 0 \\
\hline 24 & 67 & 573 & 20 & 84 & 36 & 0 & 0 \\
\hline 25 & 60 & 8 & 21 & 85 & 18 & 0 & 0 \\
\hline 26 & 49 & 13 & 22 & 86 & 24 & 0 & 0 \\
\hline 27 & 20 & 0 & 0 & 87 & 25 & 0 & 0 \\
\hline 28 & 58 & 0 & 0 & 88 & 23 & 0 & 0 \\
\hline 29 & 71 & 0 & 0 & 89 & 18 & 0 & 0 \\
\hline 30 & 73 & 19 & 1 & 90 & 38 & 0 & 0 \\
\hline 31 & 54 & 40 & 2 & 91 & 24 & 0 & 0 \\
\hline 32 & 73 & 82 & 3 & 92 & 24 & 0 & 0 \\
\hline 33 & 71 & 143 & 4 & 93 & 23 & 0 & 0 \\
\hline 34 & 56 & 208 & 5 & 94 & 22 & 0 & 0 \\
\hline 35 & 66 & 287 & 6 & 95 & 21 & 0 & 0 \\
\hline 36 & 50 & 364 & 7 & 96 & 28 & 0 & 0 \\
\hline 37 & 72 & 20 & 8 & 97 & 28 & 0 & 0 \\
\hline 38 & 74 & 62 & 9 & 98 & 33 & 0 & 0 \\
\hline 39 & 61 & 113 & 10 & 99 & 28 & 0 & 0 \\
\hline 40 & 82 & 194 & 11 & 100 & 19 & 0 & 0 \\
\hline 41 & 75 & 298 & 12 & 101 & 28 & 0 & 0 \\
\hline 42 & 70 & 420 & 13 & 102 & 34 & 0 & 0 \\
\hline 43 & 55 & 545 & 14 & 103 & 20 & 0 & 0 \\
\hline 44 & 57 & 675 & 15 & 104 & 17 & 0 & 0 \\
\hline 45 & 71 & 824 & 16 & 105 & 26 & 0 & 0 \\
\hline 46 & 58 & 979 & 17 & 106 & 19 & 0 & 0 \\
\hline 47 & 83 & 1165 & 18 & 107 & 15 & 0 & 0 \\
\hline 48 & 72 & 1371 & 19 & 108 & 28 & 0 & 0 \\
\hline 49 & 52 & 0 & 0 & 109 & 26 & 0 & 0 \\
\hline 50 & 52 & 0 & 0 & 110 & 24 & 0 & 0 \\
\hline 51 & 58 & 6 & 1 & 111 & 21 & 0 & 0 \\
\hline 52 & 89 & 49 & 2 & 112 & 19 & 0 & 0 \\
\hline 53 & 63 & 103 & 3 & 113 & 20 & 0 & 0 \\
\hline 54 & 45 & 150 & 4 & 114 & 19 & 0 & 0 \\
\hline 55 & 56 & 201 & 5 & 115 & 17 & 0 & 0 \\
\hline 56 & 76 & 276 & 6 & 116 & 29 & 0 & 0 \\
\hline 57 & 73 & 372 & 7 & 117 & 26 & 0 & 0 \\
\hline 58 & 59 & 475 & 8 & 118 & 29 & 0 & 0 \\
\hline 59 & 75 & 601 & 9 & 119 & 19 & 0 & 0 \\
\hline 60 & 47 & 722 & 10 & 120 & 23 & 0 & 0 \\
\hline
\end{tabular}

To obtained the decision interval, $\mathrm{h}$, the corresponding value of h from table $C_{2}$ of BS 5703, part 4 , when $\mathrm{k}=52$, h is equal to 50. Thus the parameters of the designed cusumare $\mathrm{k}$ $=52$ and $\mathrm{h}=50$. Therefore, an out-of- control signal will be indicate when

$$
C_{i}=\max \left[0, X_{i}-52+C_{i}-1\right]>50
$$

The plot of the cusum values with the obtained decision interval $\mathrm{h}$, is plotted in

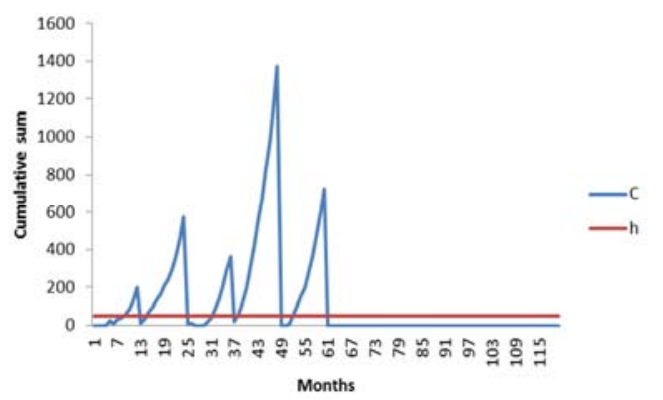

Figure 1. Cusum on Road Traffic Causalities in Osun State from the Year 2005 to 2014.
The figure above shows that road accident was out of control in $9^{\text {th }}$ month, later it was out of control from the $10^{\text {th }}$ months to $25^{\text {th }}$ month. Further discussion reveals that road accident was in control from the 61th month until date.

Exponential Weighted Moving Average (EWMA) Analysis

The value of EWMA is; $Z_{0}=24$, which is also refers as $\mu_{0}=$ 42.

$\mathrm{Z}$ is the exponential weighted moving Average of the value In general, we have found the values to be in the interval hence for the analysis we use $\lambda$ to be 0.2

$$
\begin{aligned}
& Z_{1}=\lambda X_{i}+(1-\lambda) Z_{0} \\
& Z_{1}=(0.2)(38)+(1-0.2)(42) \\
& Z_{1}=41.2 \\
& Z_{1}=41.2 \text { is the first value of } Z_{i}
\end{aligned}
$$

The other values of EWMA statistics are computed similarly for the ten years,

The control limits are found using

$$
\mathrm{UCL}=\mu_{0}+\mathrm{L} \sigma \frac{\sqrt{\lambda\left[1-(1-\lambda)^{2 i}\right.}}{\sqrt{(2-\lambda)}}
$$




$$
\begin{gathered}
\mathrm{CL}=\mu_{0} \\
\mathrm{LCL}=\mu_{0}-\mathrm{L} \sigma \frac{\sqrt{\lambda\left[1-(1-\lambda)^{2 i}\right.}}{\sqrt{(2-\lambda)}}
\end{gathered}
$$

Where $\mathrm{L}$ is the width of the control limit assumed as 2.7 22

The standard deviation of $\mathrm{X}_{1}$ values $=22.41$ approximately

For period $\mathrm{i}=1$,

The UCL $=42+59.4(0.2)$

$=53.88$

The LCL $=42-59.4(0.2)$

$=30.12$.

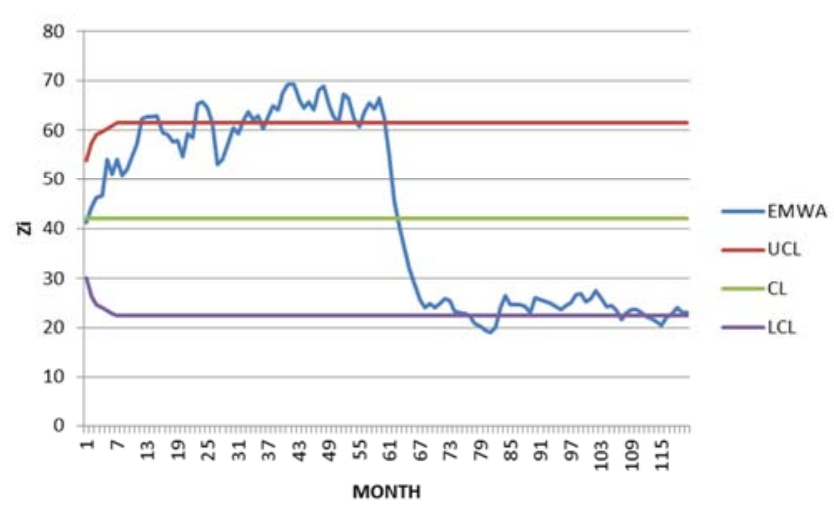

Figure 2. Graphical representation of EWMA charts of road traffic casualties in Osun State from 2005 to 2014.

The figure 2 above shows that road accident was out of control in $9^{\text {th }}$ month, later it was out of control from the $10^{\text {th }}$ months to $25^{\text {th }}$ month. Further discussion reveals that road accident was in control from the 61th month till date.

\section{Conclusion}

The results from this study indicate that both charts are capable of detecting small shift from mean level but cussum is more sensitive. More so, the points of change in the process are clearly identified and easily located on both schemes. The findings provide a proper diagnostic solution in the area of Road Traffic crash (RTC) reduction and control in Osun State Nigeria.

\section{References}

[1] Grant, E. I and Richard, S. L (1996) Statistical Quality Control. (7th Edition). The united State: McGraw-Hill, Inc.

[2] Lucas, J. M and Saccucci, M. S (1990), "Exponential Weighted Moving Average Control Schemes: Properties and Enhancements", with discussion, Technometrics, Vol.32 Pg 129.

[3] Montgomery, Douglas C. (2005). Introduction to statistical Quality Control. (14th ed.). Canada: John Wiley \& Sons, Inc.

[4] Narinderjit, S. and Sawaran, S. (2006) EMWA Control Chart in Detecting and Diagnosing a persistent Shift in a Process Mean, proceedings of the 2nd IMT-GT Regional Conference on Mathematics, Statistics and Application, Malaysia.

[5] Olatunde A. A (2013) Application of Cusum Chart for Monitoring HIV/AIDS Patients in Nigeria International Journal of Statistics and Applications Vol. 3(3): pg 77-80

[6] Osanaiye P. A and Edokpa I. W. (1998), Control of TimeBetween-Road Accidents in Kwara State of Nigeria Using Cumulative Sum Control Chart Techniques. The Journal of Nigeria Statisticians.

[7] Osanaiye P. A and C. O Talabi (1989) On some nonmanufacturing applications of counted data cumulative sum (CUSUM) control chart schemes. The Statistician 38, pp. 251257.

[8] Peden, M., McGee, R. and Sharma, G. (2002), The Ingury Chart Book: A Graphic Overview of the Global Burden of Injuries, WHO, Geneva.

[9] Peden, M., Sourfield, R., Sleef, D., Hyder, A., Jarwan, E. and Mathers, C. (2006), World Report on Road Traffic Injury Prevention, WHO, Geneva.

[10] Polanis, S. F. (1995), "Some Thoughts about traffic accidents, traffic safety and the safety management systems", ITE Journal, Vol.65 No.10.

[11] Sunday Tribune (2014,) "Crashes: When will carnage end in Nigerian roads?", Sunday Tribune, No 1,968, November 2014, Pg 2-3,10.

[12] (The) Punch (2002), "Our mournful road", The Punch, No.8, August 8, p. 15. Sanders, M. and McCormick, E. J. (1985), Human Factors in Engineering and Design, (5th ed.), McGraw-Hill, Maidenhead.

[13] World Health Organization (2008) The Health Report-Global Burden of Diseases. 